\title{
Delayed Release Mechanism of Action
}

National Cancer Institute

\section{Source}

National Cancer Institute. Delayed Release Mechanism of Action. NCI Thesaurus. Code C149427.

Release of the substance(s) at a later time than would be achieved with a conventionalrelease product, achieved by a special formulation design and/or manufacturing method; enteric-coated and other gastro-resistant products are included. 